\title{
ELECTRICAL MODELLING OF MULTILEVEL ON- CHIP INTERCONNECTIONS FOR HIGH-SPEED INTEGRATED CIRCUITS
}

\author{
K.Z. DIMOPOULOS and J.N. AVARITSIOTIS \\ National Technical University of Athens, Dep. of Electrical Engineering, Div. of Computer Science, \\ Zographou GR-15773 Athens, Greece \\ S.J. WHITE \\ GEC-Plessey Semiconductors, Tamerton Road, Roborough, Plymouth PL6 7BQ, Devon, UK \\ (Received April 7, 1991; in final form July 5, 1991)
}

\begin{abstract}
A method for the electrical parameters analysis and modelling of lossy-coupled multilayer on-chip interconnection lines at high bit rates is presented in detail. It can be used by the VLSI designer to analyze on-chip interconnections with linear, as well as nonlinear/time varying terminators and to simulate the pulse propagation characteristics in high-speed integrated circuits. First the capacitance, inductance, conductance and resistance matrices per unit length for the given multiconductor geometry is computed. A multiple coupled line model consisting of uncoupled lossy transmission lines and linear dependent current and voltage sources if finally calculated according to the capacitance, inductance, conductance and resistance matrix values computed.
\end{abstract}

\section{INTRODUCTION}

As the speed of the logic devices increases, the performance limits of the electrical interconnections become an important matter of concern. Maximizing the density of the on-chip interconnect lines can lead to undesirable coupling between adjacent signal paths. Modelling the relationship between the geometry and material properties of the interconnect medium and their electrical characteristics is important so that tradeoffs can be made between technology selection, cost and performance. Most high-performance digital circuits are simulated before construction. The core of these simulation tools is the electrical model which translates the physical structures into their equivalent electrical properties. The use of simulation is essential for high-speed VLSI circuits where isolation and interconnect regions exhibit complicated three-dimensional topographies due to the complexity of small geometry structures, because it helps to minimize the development time and cost.

Although considerable amount of work has been done in recent years on the computation on the propagation characteristics of multiple coupled strip lines, a small number ${ }^{1-12}$ of researchers have dealt with some aspects of the problem of calculation of the self and mutual line constants of on-chip interconnections, and a very limited number ${ }^{13-16}$ has tackled the problem of 3-D multilevel metallization structures. 
The purpose of this work is the detailed presentation of a self contained method developed ${ }^{17}$ for the electrical modelling of lossy-coupled multilayer on-chip interconnection lines at high bit rates, which can be used by the VLSI designer in conjunction with existing electrical simulation packages. The method presented here takes as input a given geometry of a lossy coupled 3-D interconnection system and produces as a final result a model consisting of lumped elements which can be included in any SPICE-like analog simulation package. The formulation of lossy coupled multiconductor interconnection lines, which at high bit rates ( $\sim \mathrm{GBit} / \mathrm{sec})$ must be considered as transmission lines, is obtained using a free-space Green's function in conjunction with total charge on the conductor-to-dielectric interfaces and polarization charge on the dielectric interfaces. The solution is derived by applying the method of moments ${ }^{18}$ and it includes the effects of signal attenuation and signal dispersion encountered in fast transient waveform propagation.

\section{MULTILEVEL PARALLEL LINES}

For a set of coupled lines, the induced signal on the inactivated lines depends on the coupling coefficients and the slew rate of the propagation signal. In IC technology, the separation between the lines is about a few micrometers and the distance between the conductors and the ground plane is about several hundred micrometers; therefore, the coupling coefficients are very important.

Let us consider firstly an arbitrary number Nc of parallel metallization paths which are embedded in an arbitrary number Nd of dielectric layers, as shown in Fig. 1. The length of the paths is considered to be large in comparison to their cross-section of dimensions, and the orthogonal cross section is uniform in the $\mathrm{z}$ direction. That reduces the problem to a two-dimensional one. The permittivity of the $\mathrm{j}$-th dielectric layer is $\varepsilon_{\mathrm{j}}$. The uppermost dielectric extends to $\mathrm{y}=\infty$. The lower ground plane extents from $\mathrm{x}=-\infty$ to $\mathrm{x}=\infty$.

An interconnect system tends to require complex modelling because the conductor material is not lossless and the lines can be coupled both capacitively and inductively. The finite conductivity of the conductor results in a variation of the

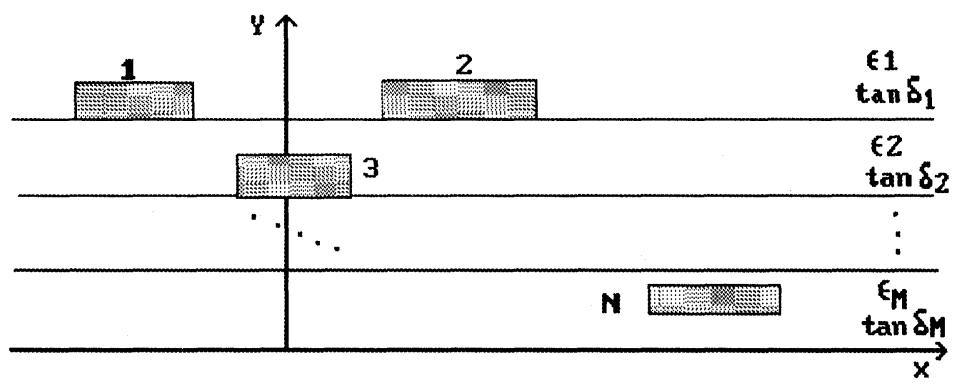

FIGURE 1 Multiconductors in multilayer interconnection system 
current density distribution in the conductor. Skin effect loss (conductor loss) and dielectric loss as well as different signal phase velocities at high frequency make the interconnect resistance and capacitance frequency dependent.

A single interconnection line and its equivalent circuit model per unit length of the structure for frequency-dependence analysis are shown in Fig. 2 (a) and (b) respectively. In Fig. 2 (b), $\mathrm{R}$ represents the interconnection line series resistance, $\mathrm{L}$ is the interconnect line inductance resulting from the propagating electromagnetic field, $\mathrm{G}$ is the substrate shunt conductance, and $\mathrm{C}$ is the substrate capacitance.

Voltages and currents for such a system are described by the following set of differential equations ${ }^{19}$

$\left.\frac{\theta \mathrm{u}]}{\theta \mathrm{z}}=-[\mathrm{R}] \mathrm{i}\right]-[\mathrm{L}] \frac{\theta \mathrm{i}]}{\theta \mathrm{t}}$

$\left.\frac{\theta \mathrm{i}]}{\theta \mathrm{z}}=-[\mathrm{G}] \mathrm{u}\right]-[\mathrm{C}] \frac{\theta \mathrm{u}]}{\theta \mathrm{t}}$

Here vectors $u]=\left[\mathrm{u}_{1}, \mathrm{u}_{2}, \ldots \mathrm{u}_{\mathrm{n}}\right]^{\mathrm{T}}$ and $\left.\mathrm{i}\right]=\left[\mathrm{i}_{1}, \mathrm{i}_{2}, \ldots \mathrm{i}_{\mathrm{n}}\right]^{\mathrm{T}}$ represent voltages and currents on the lines. The superscript $\mathrm{T}$ represents the transpose. [R], [L], [G], and $[\mathrm{C}]$ are the series resistance, series inductance, shunt conductance, and shunt capacitance matrices, respectively, whose elements represent the equivalent self-
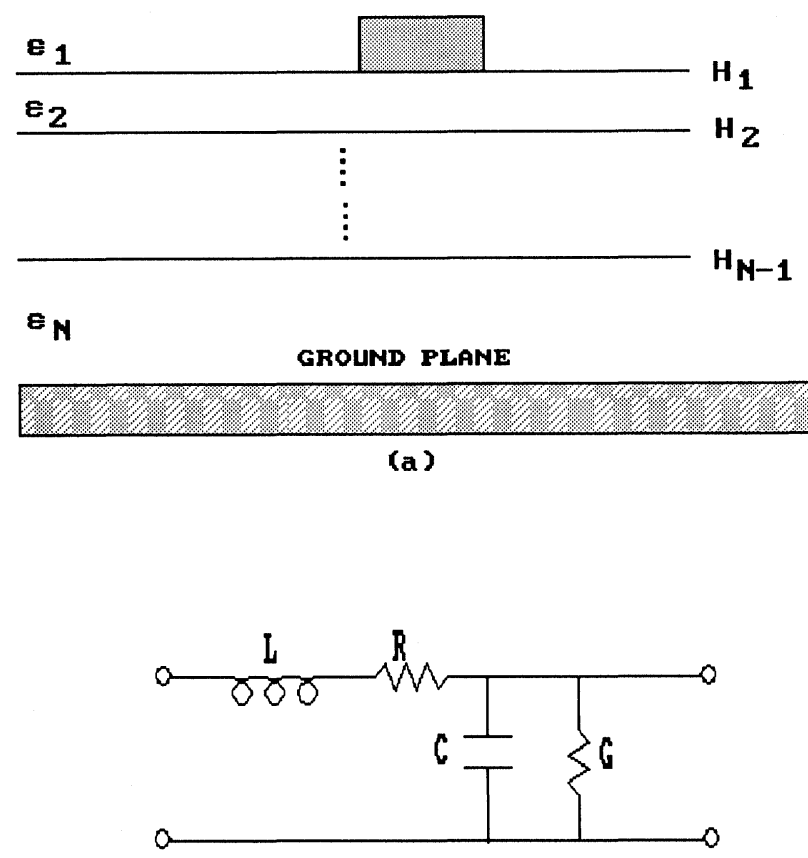

(b)

FIGURE 2 Single interconnection line (a) Topology (b) Electrical Equivalent Model per unit length 
and mutual parameters per unit length of the interconnections. After the calculation of $[\mathrm{C}],[\mathrm{L}],[\mathrm{G}]$, and $[\mathrm{R}]$, as it is explained in the following, the system of the former differential equations is solved obtaining the values of depended voltage and current sources as well as the delay and the characteristic admittance of the uncoupled transmission lines for the equivalent $2 n$-multiport model.

It is worth noting that quasi-TEM mode propagation has been assumed throughout the analysis. Since a static analysis would be valid for low frequencies only, a number of frequency dependent effects that occur at high frequencies have been included, like frequency dependencies of both the effective dielectric constant and the losses, as well as the frequency dispersion of the resistance of the metal conductors (skin effect). With the common used substrate resistivities in the IC technology, and in the frequency range used $(<100 \mathrm{GHz})$ we avoid the "slow-wave" and the "skin effect" modes as described by Hasegawa ${ }^{20}$. This approach ensures that the analysis is valid up to the frequency where non-TEM modes can propagate in the interconnection lines, i.e. the cutoff frequency for the surface wave mode. It has been shown that for a $450 \mu \mathrm{m}$ thick Si substrate wafer with $10 \Omega \mathrm{cm}$ resistivity, the cutoff frequency is $50 \mathrm{GHz}^{21}$.

\section{II.1. Calculation of the Capacitance Matrix}

Several simple configurations have been analyzed by analytic techniques such as conformal mapping, but there are theoretical difficulties associated with the boundary conditions imposed upon the electric fields at the dielectric interfaces. Several numerical techniques such as the finite-difference method, finite-element method, variational method, spectral-domain techniques, and the method of moments may be used to solve the two-dimensional (i.e., structure long in one dimension) Laplace equation to extract the capacitance parameters of a given packaging geometries.

Here, the elements of the capacitance matrix are calculated by relating the free charge per unit length of surface on the conductors to the potentials of the conductors. The ij-th element of the capacitance matrix is the free charge per unit length of surface on the $i$-th conductor when the potential of the $j$-th conductor is one volt and the other conductors are grounded.

At any point $r$ on the i-th conductor-to-dielectric interface, the potential $\Phi_{\mathrm{i}}$ due to the combination of $\sigma_{\mathrm{T}}$ and the image of $\sigma_{\mathrm{T}}$ above the lower ground plane is assumed to be constant (first boundary condition), and it is given by the following equation which is derived from the appropriate Green's function applying the method of images ${ }^{22}$

$\frac{1}{2 \pi \varepsilon_{0}} \sum_{\mathrm{j}=1}^{\mathrm{N}} \int_{\mathrm{S}_{\mathrm{j}}} \sigma_{\mathrm{T}}\left(r^{\prime}\right) \ln \left[\frac{\left|r-\hat{r}^{\prime}\right|}{\left|r-r^{\prime}\right|}\right] \mathrm{d} \mathrm{S}^{\prime}=\phi \mathrm{i}$,

where $S_{\mathrm{j}}$ is the boundary of the $\mathrm{j}$-th interface in the xy plane, $\mathrm{dS}^{\prime}$ is the differential element of length at $r^{\prime}$ on $S_{\mathrm{j}}, \hat{r}^{\prime}$ is the image of $r^{\prime}$ about the lower ground plane, and $\mathrm{N}$ is the total number of interfaces $\left(\mathrm{N}_{\mathrm{c}}+\mathrm{N}_{\mathrm{d}}-1\right)$.

The second boundary condition refers to the y component of the displacement 
vector $D(r)$ which is assumed to be continuous across each i-th dielectric-to-dielectric interface, thus

$\left.\left(\varepsilon_{\mathrm{i}-\mathrm{N}_{\mathrm{c}}}\right) \frac{\theta \phi(r)}{\theta \mathrm{y}}\right|_{+} u_{\mathrm{y}}=\left.\left(\varepsilon_{\mathrm{i}+1-\mathrm{Nc}}\right) \frac{\theta \phi(r)}{\theta \mathrm{y}}\right|_{-} \quad \begin{aligned} & r \text { on } \mathrm{S}_{\mathrm{i}} \\ & \mathrm{i}=\mathrm{N}_{\mathrm{c}}+1, \mathrm{~N}_{\mathrm{c}}+2, \ldots \mathrm{N}\end{aligned}$

where $\varepsilon_{\mathrm{i}-\mathrm{Nc}}$ is the permittivity on the upper side of $\mathrm{S}_{\mathrm{i}}$, and $-\theta \Phi(r) / \theta \mathrm{y}_{+}$is the normal component of the electric field on the upper side of $S_{i}$.

The electric field $E(r)$ when $r$ approaches the interface $\mathrm{S}_{\mathrm{i}}$ is given by the following equation

$$
\begin{array}{r}
\frac{\left(\varepsilon_{\mathrm{i}-\mathrm{Nc}}+\varepsilon_{\mathrm{i}+1-\mathrm{Nc}}\right)}{2 \varepsilon_{0}\left(\varepsilon_{\mathrm{i}-\mathrm{Nc}}-\varepsilon_{\mathrm{i}+1-\mathrm{Nc}}\right)} \sigma_{\mathrm{T}}(r)+\frac{1}{2 \mathrm{n} \varepsilon_{0}} \sum_{\mathrm{j}=1}^{\mathrm{N}} \int_{\mathrm{S}_{\mathrm{i}}} \sigma_{\mathrm{T}}\left(r^{\prime}\right)\left[\frac{r-\hat{r}^{\prime}}{\left|r-\hat{r}^{\prime}\right|^{2}}-\frac{r-r^{\prime}}{\left|r-r^{\prime}\right|^{2}}\right] u_{\mathrm{y}} \mathrm{dS}^{\prime}=0, \\
\begin{array}{l}
r \text { on } \mathrm{S}_{\mathrm{i}} \\
\mathrm{i}=\mathrm{N}_{\mathrm{c}}+1, \ldots, \mathrm{N}
\end{array}
\end{array}
$$

Equations (3) and (5) constitute a set of $\mathrm{N}$ integral equations for the unknown total charge $\sigma_{\mathrm{T}}$ per unit area on the interfaces whose contours are $\mathrm{S}_{\mathrm{i}}$. Since (3) and (5) are linear, and assuming that the potential $\Phi_{\mathrm{i}}$ is unity and all other potentials are zero, we obtain

$\sigma_{\mathrm{T}}=\sum_{\mathrm{i}=1}^{\mathrm{Nc}} \sigma_{\mathrm{T}}^{(\mathrm{i})} \phi_{\mathrm{i}}$

Consequently, the charge $Q_{i}$ per unit length on the $\mathrm{i}$-th conductor is given by

$\mathrm{Q}_{\mathrm{i}}=\int_{\mathrm{Si}} \sigma_{\mathrm{F}}(r) \mathrm{dS}_{\mathrm{i}}=\sum_{\mathrm{j}=1}^{\mathrm{N}_{\mathrm{c}}} \mathrm{C}_{\mathrm{ij}} \phi_{\mathrm{i}} \quad \mathrm{i}=1,2, \ldots, \mathrm{N}_{\mathrm{c}}$

where $\sigma_{\mathrm{F}}$ is the free charge density on the surface of each conductor and it is given by

$\sigma_{\mathrm{F}}(r)=\frac{\varepsilon(r)}{\varepsilon_{0}} \sigma_{\mathrm{T}}(r)$

The capacitance coefficients $C_{i j}$ between conductors $i$ and $j$ are

$\mathrm{C}_{\mathrm{ij}}=\int_{\mathrm{S}_{\mathrm{i}}} \frac{\varepsilon(r)}{\varepsilon_{0}} \sigma_{\mathrm{T}}^{(\mathrm{j})}(r) \mathrm{dS} \mathrm{S}_{\mathrm{i}}$

If an upper ground plane exists, it is considered as an ordinary conductor $\mathrm{j}$; so that the reduced capacitance matrix $[\mathrm{C}]$ is simply found by deleting the $\mathrm{j}$-th row and column.

For the calculation of the $C_{i j}$ the integral equations (3) and (5) can be solved 
numerically for $\sigma_{\mathrm{T}}$ by the method of moments. A solution for $\sigma_{\mathrm{T}}$ is sought of the form

$\sigma_{\mathrm{T}}(r)=\sum_{\mathrm{n}=1}^{\mathrm{J}} \sigma_{\mathrm{Tn}} \mathrm{P}_{\mathrm{n}}(r)$

where $\mathrm{P}_{\mathrm{n}}(r)$ are unit pulse functions which cover $\mathrm{S}_{\mathrm{j}}$. The dielectric layers are now truncated at a finite negative value of $\mathrm{x}$ and a finite positive value of $\mathrm{x}$ so that only pulse functions of finite domain are needed.

At any differential element $\mathrm{m}$, we assume that

$\mathrm{P}_{\mathrm{m}}=1$

$\mathrm{P}_{\mathrm{n}}=0, \quad \mathrm{n}=1,2, \ldots, \mathrm{m}-1, \mathrm{~m}+1, \ldots, \mathrm{J}$

It follows from (10) and (11) that

$\sigma_{\mathrm{T}}=\sigma_{\mathrm{Tm}}$

Let $r_{\mathrm{m}}$ be a point on the differential element $\mathrm{m}$ of the domain of $\mathrm{P}_{\mathrm{m}}(r)$ for $\mathrm{m}=$ $1,2, \ldots, \mathrm{J}$. Substituting (10) for $\sigma_{\mathrm{T}}$ in (3) at $r=r_{\mathrm{m}}$, for $\mathrm{m}=1,2, \ldots, \mathrm{N}_{1}$, we obtain

$\sum_{\mathrm{n}=1}^{\mathrm{J}} \mathrm{M}_{\mathrm{mn}} \sigma_{\mathrm{Tn}}=\phi \mathrm{i}, \quad \mathrm{m}=1,2, \ldots, \mathrm{N}_{1}$

where $\mathrm{i}$ is such that $r_{\mathrm{m}}$ is on $\mathrm{S}_{\mathrm{i}}$, and

$\mathbf{M}_{\mathrm{mn}}=\frac{1}{2 \pi \varepsilon_{0}} \int_{\Delta \mathrm{S}_{\mathrm{n}}} \int_{\Delta \mathrm{S}_{\mathrm{m}}} \ln \frac{\left|r_{\mathrm{m}}-\hat{r}_{\mathrm{n}}^{\prime}\right|}{\left|r_{\mathrm{m}}-r_{\mathrm{n}}^{\prime}\right|} \mathrm{dS}_{\mathrm{n}} \mathrm{dS}_{\mathrm{m}} \quad \begin{aligned} & \mathrm{m}=1,2, \ldots, \mathrm{N}_{1} \\ & \mathrm{n}=1,2, \ldots, \mathrm{N}\end{aligned}$

where $\Delta S_{n}$ is the domain of $P_{n}(r)$. (For the evaluation of both this double integral and the one associated with equation 16, see Appendix A.)

Substituting (10) for $\sigma_{\mathrm{T}}$ in (5) and then enforcing (5) at $r=r_{\mathrm{m}}$ for $\mathrm{m}=\mathrm{N}_{1}+$ $1, \mathrm{~N}_{1}+2, \ldots, \mathrm{J}$, we obtain

$\sum_{\mathrm{n}=1}^{\mathrm{J}} \mathrm{M}_{\mathrm{mn}} \sigma_{\mathrm{Tn}}=0, \quad \mathrm{~m}=\mathrm{N}_{1}+1, \ldots, \mathrm{J}$

where, $\mathbf{M}_{\mathrm{mn}}$ is given by

$$
\begin{aligned}
\mathrm{M}_{\mathrm{mn}}= & \frac{\varepsilon_{\mathrm{i}-\mathrm{Nc}}+\varepsilon_{\mathrm{i}+1-\mathrm{Nc}}}{2 \varepsilon_{0}\left(\varepsilon_{\mathrm{i}-\mathrm{Nc}}-\varepsilon_{\mathrm{i}+1-\mathrm{Nc}}\right)} \delta_{\mathrm{mn}}-\frac{1}{2 \pi \varepsilon_{0}} \int_{\Delta \mathrm{S}_{\mathrm{n}}} \int_{\Delta \mathrm{S}_{\mathrm{m}}}\left|\frac{r_{\mathrm{m}}-\hat{r}_{\mathrm{n}}^{\prime}}{\left|r_{\mathrm{m}}-\hat{r}_{\mathrm{n}}^{\prime}\right|^{2}}\right| u_{\mathrm{y}} \mathrm{dS}_{\mathrm{n}} \mathrm{dS} \mathrm{S}_{\mathrm{m}} \\
& \quad-\frac{1}{2 \pi \varepsilon_{0}} \int_{\Delta \mathrm{S}_{\mathrm{n}}} \int_{\Delta \mathrm{S}_{\mathrm{m}}}\left|\frac{r_{\mathrm{m}}-r_{\mathrm{n}}^{\prime}}{\left|r_{\mathrm{m}}-r_{\mathrm{n}}^{\prime}\right|^{2}}\right| u_{\mathrm{y}} \mathrm{dS}_{\mathrm{n}} \mathrm{dS}_{\mathrm{m}} \quad \mathrm{m}=\mathrm{N}_{1}+1, \ldots, \mathrm{J}
\end{aligned}
$$


with

$\Delta_{\mathrm{mn}}=\left[\begin{array}{ll}1 & \mathrm{~m}=\mathrm{n} \\ 0 & \mathrm{~m} \neq \mathrm{n}\end{array} \quad\right.$ (Kroeneker operator)

In (16), $\mathrm{i}$ is such that $r_{\mathrm{m}}$ is on $\Delta \mathrm{S}_{\mathrm{m}}$, and $r_{\mathrm{n}}^{\prime}$ on $\Delta \mathrm{S}_{\mathrm{n}}$.

After $\mathbf{M}_{\mathrm{mn}}$ has been calculated for $\mathrm{m}=1,2, \ldots, \mathrm{J}$ and $\mathrm{n}=1,2, \ldots, \mathrm{J}$, (13) and (15) combine to form $J$ simultaneous equations in the $J$ unknowns $\sigma_{\mathrm{Tn}}$. The solution is of the form

$\sigma_{\mathrm{Tn}}=\sum_{\mathrm{i}=1}^{\mathrm{Nc}} \sigma_{\mathrm{Tn}}^{(\mathrm{i})} \phi_{\mathrm{i}}$

where $\sigma_{\mathrm{Tn}}^{(\mathrm{i})}$ is the solution which would result if $\Phi_{\mathrm{i}}$ were unity and all other $\Phi$ 's were zero.

\section{II.2. Calculation of the Inductance Matrix}

The ij-th element of the inductance matrix [L] represents the magnetic flux passing between a unit length of the $\mathrm{i}$-th conductor and the lower ground plane when one ampere of net $\mathrm{z}$-directed electric current flows on the $\mathrm{j}$-th conductor and there is no net $\mathrm{z}$-directed electric current on any of the other conductors. It is known that ${ }^{11}$

$[\mathrm{L}]=\mu_{0} \varepsilon_{0}\left[\mathrm{C}_{0}\right]^{-1}$

where $\mathrm{C}_{0}$ is the capacitance matrix which would result if all dielectric layers were replaced by free space, $\mu_{0}$ and $\varepsilon_{0}$ are the permeability and the permittivity of free space, respectively.

\section{II.3. Calculation of the Conductance Matrix}

The complex permittivity of the $\mathrm{i}$-th loading layer given by $\varepsilon_{\mathrm{i}}=\varepsilon_{\mathrm{i}}^{\prime}-\mathrm{j} \varepsilon_{\mathrm{i}}^{\prime \prime}=\varepsilon_{\mathrm{i}}^{\prime}$ $\left(1-\mathrm{j} \tan \delta_{\mathrm{i}}\right)$ where, $\varepsilon_{\mathrm{i}}^{\prime}$ and $-\varepsilon_{\mathrm{i}}^{\prime \prime}$ are the real and imaginary parts of $\varepsilon_{\mathrm{i}}$, and tan $\delta_{\mathrm{i}}=\varepsilon_{\mathrm{i}}^{\prime \prime} / \varepsilon_{\mathrm{i}}^{\prime}$ is the loss tangent, the so-called dissipation factor, which it represents the losses of the dielectric medium, consequently

$\mathrm{j} \omega\left[\mathrm{C}^{\prime}\right]=[\mathrm{G}+\mathrm{j} \omega \mathrm{C}]$

The conductance which is the real part of (20), is calculated as

$$
[\mathrm{G}]=-\operatorname{Im}\left[\omega \mathrm{C}^{\prime}\right]
$$

\section{II.4. Calculation of the Resistance Matrix}

The resistance matrix is calculated by applying the perturbation theory ${ }^{23}$ to the loss-free line system which is described by the following eigenvalue equations

$$
[\mathrm{C}][\mathrm{L}] \mathrm{I}^{0}=\frac{1}{\mathrm{u}_{\mathrm{p}}^{2}} \mathrm{I}^{0}
$$


$[\mathrm{L}][\mathrm{C}] \mathrm{V}^{0}=\frac{1}{\mathrm{u}_{\mathrm{p}}^{2}} \mathrm{~V}^{0}$

where the superscripts ${ }^{0}$ denote unperturbed, and $v_{\mathrm{p}}$ is the phase velocity. It is important to note that the phase velocities $v_{\mathrm{p}}$ are generally different for each transmission mode, since the transmission line has several different dielectrics.

The time-average power transmitted along the line, is $\mathrm{P}_{\mathrm{T}}=\operatorname{Re}\left(\left(\mathrm{I}^{\mathrm{T}}\right)^{*} \mathrm{~V}\right)$ and thus, the unperturbed power flow is $\mathrm{P}_{\mathrm{T}}^{0}=\mathrm{I}^{\mathrm{T} 0} \mathrm{~V}^{0}$.

The power loss per unit length, $P_{c}$, of the transmission line can be calculated by the following formula

$P_{c}=\sum_{i} R s \int_{S_{i}} J_{i}^{2} d S$

where Rs is the surface resistance of the metal, $J_{i}$ is the current density on the $\mathrm{i}$-th conductor, and the integral is taken over all metal surfaces $\mathrm{S}_{\mathrm{i}}$. Equation (24) is evaluated by using the moment solution. Once $P_{c}$ is evaluated for a given mode, attenuation due to conductor losses is given by

$a_{c}=\frac{P_{c}}{2 P_{T}^{0}}$

The resistive matrix per unit length $[R]$ can now be evaluated, if $G<<\omega C$ then

$\left(\mathrm{a}_{\mathrm{c}}+\mathrm{j} \beta\right)^{2} \mathrm{~V}=[\mathrm{R}+\mathrm{j} \omega \mathrm{L}][\mathrm{j} \omega \mathrm{C}] \mathrm{V}$

In the TEM approximation and at high enough frequencies the behavior is "lowloss" (Hasegawa ${ }^{20}$ ), thus, we can take $\mathrm{V} \approx \mathrm{V}^{0}$ to be real, setting $\beta \approx \beta^{0}$ and using (22), equation (26) reduces to

$2 \mathrm{a}_{\mathrm{c}} \mathrm{V}^{0} \approx[\mathrm{R}] \mathrm{I}^{0}$

from which [R] can be calculated since $\alpha, \mathrm{V}^{0}$, and $\mathrm{I}^{0}$ are known for each mode.

\section{II.5 Edge Effects}

The approximation of $\sigma_{\mathrm{T}}$ by a constant charge density, is particularly poor near the sharp convex corners of the conductors due to the steep slope of the charge density surface caused by the singularity. Elements decreasing in size towards the corners have been used before to obtain more accurate capacitance values (i.e. ${ }^{8}$ ).

A typical residual voltage for dielectric substrate of $e_{r}=1.0$ and microstrip width-to-height ratio $\mathrm{w} / \mathrm{h}=1$ can be found $\mathrm{in}^{7}$. They have shown that moving further away from the discontinuity, a small amount of negative potential residual appears which eventually reduces down to zero. This is due to the iteration between the two normal microstrip-like distributions and is most noticeable for small $e_{r}$ and 
w/h. They have also shown using numerical experimentals the most significant part of the excess charge is located near the outer edge of the corner region.

In order to take into account these effects, the conductor surfaces are divided into elementary subsections of varying width which must be relatively small in outer corner and the edges. Using the formula $\mathrm{by}^{8}$, we chose the following criterion for the size of $\Delta \mathrm{S}$ of each subsection

$\Delta S=a \sqrt{1-\left[\frac{\mathrm{W} / 2-\mathrm{x}-\mathrm{x}_{\min }}{\mathrm{W} / 2}\right]^{2}}$

where coefficient $\alpha$ is determined by fixing the width of the smallest partition $\Delta \mathrm{x}_{1}$ at the outer surface corner. The other partition widths are calculated by the recurrent relation

$\Delta S_{n+1}=a \sqrt{1-\left[\frac{D_{n}-\Delta S_{n+1}}{W}\right]^{2}}$

where

$D_{n}=2\left[x_{n}-\left(x_{\max }+x_{\min }\right) / 2\right]-\Delta S_{n}$

$\mathrm{In}^{8}$, they shown that the smallest partition width must comply with

$\Delta \mathrm{S}_{1}=\mathrm{W} / \mathrm{N}$

where

$$
\begin{array}{ll}
N=20 / \beta & \text { for } W / H \leq 1 \\
N=[20+4(W / H-1)] / \beta & \text { for } W / H>1
\end{array}
$$

$\beta$ is a coefficient that allows us to have the desired accuracy. For example, with $\beta$ $=1$, the error is less than 1 percent even if the medium is not homogeneous.

\section{THE EQUIVALENT MULTIPORT MODEL}

Having calculated the self and mutual line constants and taking into account that the uniform system under consideration is linear and time invariant, equations (1) and (2) can be considered in the frequency domain and consequently V] and I] may be defined as the corresponding voltage and current vectors. For $\mathrm{e}^{\mathrm{j} \omega t-\gamma \mathrm{z}}$ variation, and taking the second derivatives of (1) and (2) we obtain

$$
\begin{aligned}
& \left.\frac{\left.\mathrm{d}^{2} \mathrm{~V}\right]}{\mathrm{dz}^{2}}=\left[\mathrm{Z}_{\mathrm{S}}\right]\left[\mathrm{Y}_{\mathrm{SH}}\right] \mathrm{V}\right] \\
& \left.\frac{\left.\mathrm{d}^{2} \mathrm{I}\right]}{\mathrm{dz}^{2}}=\left[\mathrm{Y}_{\mathrm{SH}}\right]\left[\mathrm{Z}_{\mathrm{S}}\right] \mathrm{I}\right]
\end{aligned}
$$


where $\left[Z_{S}\right]=[R]+j \omega[L],\left[Y_{S H}\right]=[G]+j \omega[C]$, are the series impedance and the shunt admittance per unit length respectively. Equation (2) represented the conservation of charge, and links the longitudinal variation of the line current dI between the ends of the section $\mathrm{dz}$ with the time derivative of the line voltage. Equation (1) was a statement of Faraday's law of induction, and relates the longitudinal of the line voltage change $\mathrm{dV}$ over the length of the section $\mathrm{dz}$, to the time derivative of the line current.

To obtain the modes of the transmission line, we seek solutions of equations (33) and (34) of the form

$\mathrm{I}=\hat{\mathrm{I}}^{\mathrm{j} \omega t-\mathrm{yz}}$

$\mathrm{V}=\hat{\mathrm{V}} \mathrm{e}^{\mathrm{j} \omega t-\mathrm{yz}}$

where $\gamma$ is the propagation factor and it is equal to $\left[\mathrm{Z}_{\mathrm{S}} \mathrm{Y}_{\mathrm{SH}}\right]^{1 / 2}$. Substituting equations (35) and (36) into (1) and (2), we have

$$
\begin{aligned}
& \gamma \hat{\mathbf{I}}=[\mathrm{G}+\mathbf{j} \omega \mathrm{C}] \hat{\mathbf{V}} \\
& \gamma \hat{\mathbf{V}}=[\mathbf{R}+\mathbf{j} \omega \mathrm{L}] \hat{\mathbf{I}}
\end{aligned}
$$

Substituting for V from (38) into (37), and vice versa, we obtain

$$
\begin{aligned}
& {[G+j \omega C][R+j \omega L] \hat{\mathbf{I}}=\gamma^{2} \hat{\mathbf{I}}} \\
& {[R+j \omega L][G+j \omega C] \hat{\mathbf{V}}=\gamma^{2} \hat{\mathbf{V}}}
\end{aligned}
$$

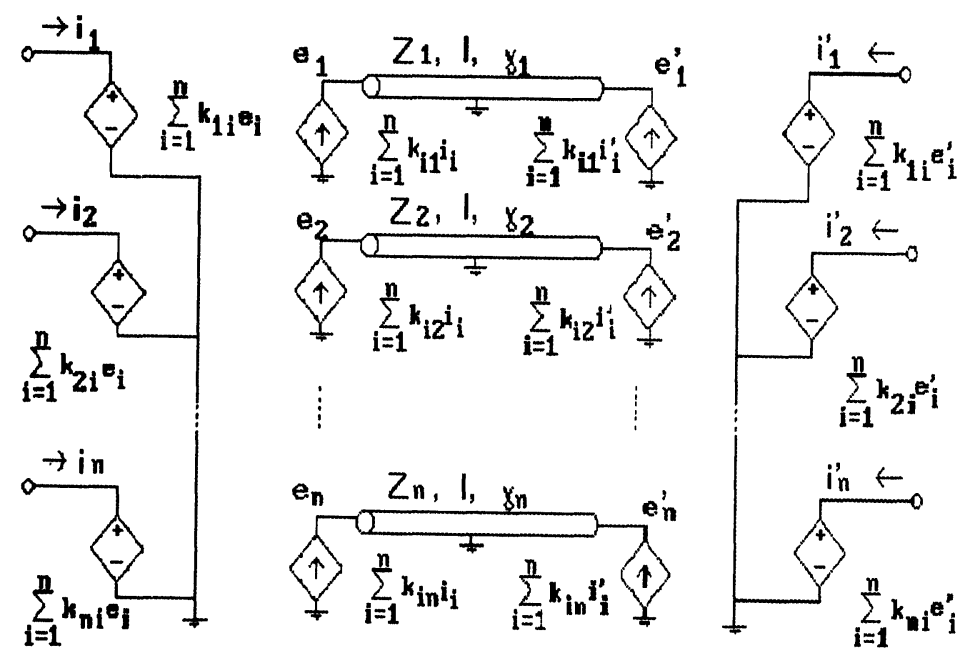

FIGURE 3 Electrical equivalent multiport model 
Let $\left[\mathrm{M}_{v}\right]$ be the complex eigenvector matrix associated with the characteristic matrix $\left[\mathrm{Z}_{\mathrm{S}}\right]\left[\mathrm{Y}_{\mathrm{SH}}\right]$. The voltage and current eigenvectors e] and $\left.\mathrm{j}\right]$, respectively, are the solutions of the decoupled set of equations ${ }^{24}$

$$
\begin{aligned}
& \left.\frac{\mathrm{de}]}{\mathrm{dz}}=-\operatorname{diag}\left[\mathrm{Y}_{\mathrm{k}} / \mathrm{y}_{\mathrm{k}}\right] \mathrm{j}\right] \\
& \left.\frac{\mathrm{dj}]}{\mathrm{dz}}=-\operatorname{diag}\left[\mathrm{Y}_{\mathrm{k}} \mathrm{y}_{\mathrm{k}}\right] \mathrm{e}\right] \\
& {\left[\begin{array}{c}
\mathrm{V}] \\
\mathrm{I}]
\end{array}\right]=\left[\begin{array}{ll}
{\left[\mathrm{M}_{\mathrm{U}}\right]} & {[0]} \\
{[0]} & \left\{\left[\mathrm{M}_{\mathrm{U}}\right]^{\mathrm{T}}\right\}^{-1}
\end{array}\right]\left[\begin{array}{c}
\mathrm{e}] \\
\mathrm{j}]
\end{array}\right]}
\end{aligned}
$$

where $\gamma_{\mathrm{k}}$ is the propagation constant for the k-th mode and is the square root of the $\mathrm{k}$-th eigenvalue of the $\left[\mathrm{Z}_{\mathrm{S}}\right]\left[\mathrm{Y}_{\mathrm{SH}}\right]$ matrix and $\mathrm{y}_{\mathrm{k}}$ is the characteristic admittance of the $\mathrm{k}$-th mode and is the corresponding element of the diagonal matrix $\left[\mathrm{Y}_{\mathrm{k}}\right]$ which is given by ${ }^{25}$

$$
\left[\mathrm{Y}_{\mathrm{k}}\right]=\left[\mathrm{M}_{\mathrm{U}}\right]^{-1}\left[\mathrm{Y}_{\mathrm{SH}}\right]\left[\mathrm{M}_{\mathrm{U}}\right]
$$

The previous equations lead to the $2 \mathrm{n}$ port circuit model representing $\mathrm{n}$ lossy parallel lines as shown in Fig. 3. The important figure of the presented method is the conversion of the coupled transmission lines into a model that consists of lossy uncoupled lines and a modal decoupling network at the input and a complementary coupling network at the output end. Thus the time domain transient behavior of the coupled transmission lines can be analyzed by applying the fundamental Kirchoff's laws.

\section{MULTILEVEL CROSSED LINES}

The crossing of two interconnection lines located at the interfaces of (or) embedded in different dielectric layers may be characterized by an equivalent $\Pi$-type capacitive

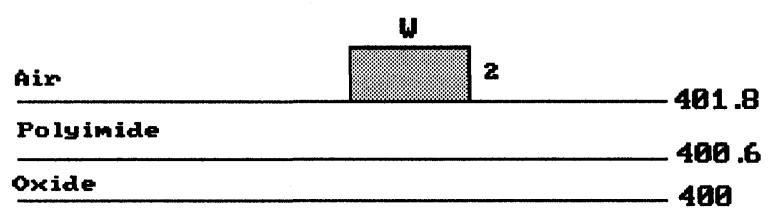

Silicon

GROUND PLANE

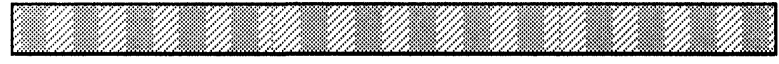

FIGURE 4 Single line example topology 


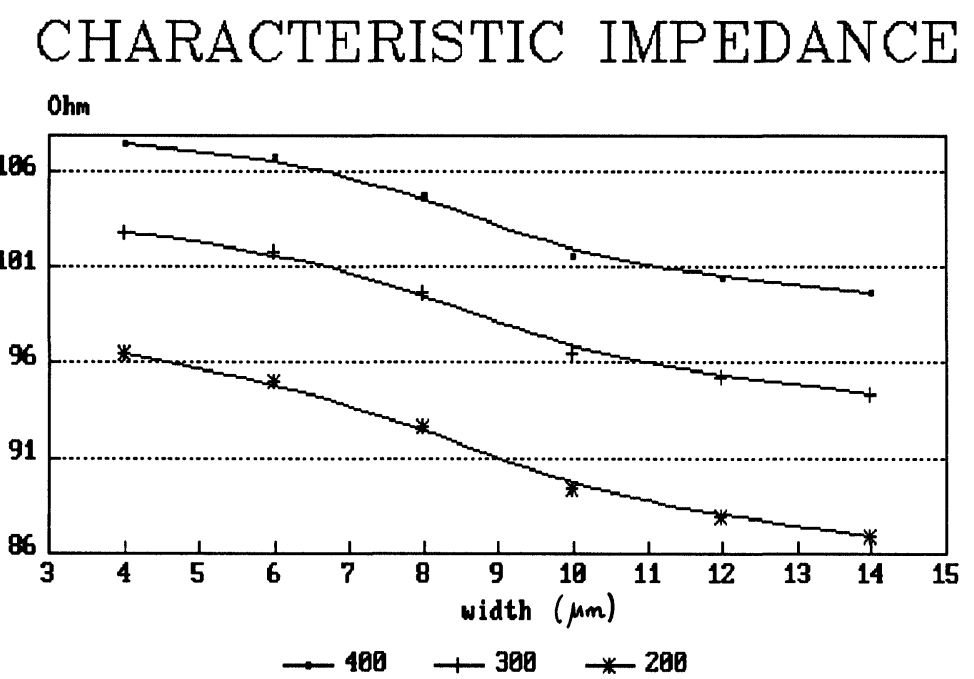

FIGURE 5 Characteristic impedance vs. width of the conductor

circuit $^{14}$. Extension of equations (3) and (5) to 3-D cases gives equations (45) and (46) respectively, i.e.

$\frac{1}{4 \pi \varepsilon_{0}} \sum_{\mathrm{j}=1}^{\mathrm{N}} \int_{\mathrm{S}_{\mathrm{j}}} \sigma_{\mathrm{T}}\left(r^{\prime}\right)\left[\frac{1}{\left|r-\hat{r}^{\prime}\right|}-\frac{1}{\left|r-r^{\prime}\right|}\right] \mathrm{d} \mathrm{S}^{\prime}=\phi \mathrm{i}$,

where $S_{j}$ is the surface of the $j$-th interface in the xy plane, $d S^{\prime}$ is the surface differential element at $r^{\prime}$ on $\mathrm{S}_{\mathrm{j}}, \hat{r}^{\prime}$ is the image of $r^{\prime}$ about the lower ground plane,

\section{VELOCITIES}

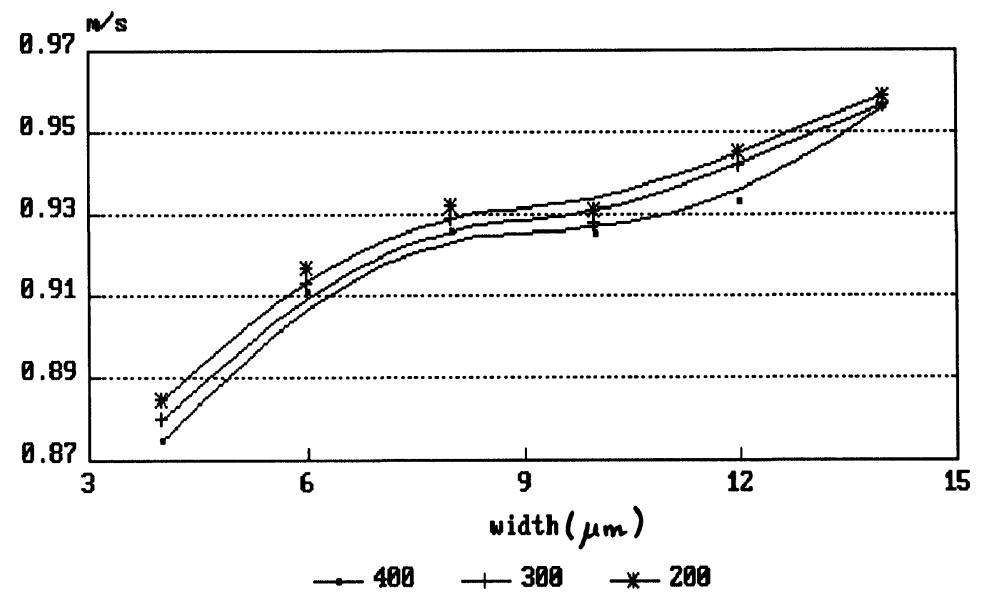

FIGURE 6 Transmission velocities vs. conductor width 
and $\mathrm{N}$ is the total number of interfaces $\left(\mathrm{N}_{\mathrm{c}}+\mathrm{N}_{\mathrm{d}}-1\right)$, with the unknowns, now, representing the surface charge in two dimensions; and

$$
\begin{aligned}
& \frac{\left(\varepsilon_{\mathrm{i}-\mathrm{Nc}}+\varepsilon_{\mathrm{i}+1-\mathrm{Nc}}\right)}{2 \varepsilon_{0}\left(\varepsilon_{\mathrm{i}-\mathrm{Nc}}-\varepsilon_{\mathrm{i}+1-\mathrm{Nc}}\right)} \sigma_{\mathrm{T}}(r) \\
& +\frac{1}{2 \pi \varepsilon_{0}} \sum_{\mathrm{j}=1}^{\mathrm{N}} \int_{\mathrm{S}_{\mathrm{i}}} \sigma_{\mathrm{T}}\left(r^{\prime}\right)\left[\frac{r-\hat{r}^{\prime}}{\left|r-\hat{r}^{\prime}\right|^{2}}-\frac{r-r^{\prime}}{\left|r-r^{\prime}\right|^{2}}\right] u_{\mathrm{y}} \mathrm{dS}^{\prime}=0, \\
& \quad \begin{array}{r}
r \text { on } \mathrm{S}_{\mathrm{i}} \\
\mathrm{i}=\mathrm{N}_{\mathrm{c}}+1, \ldots, \mathrm{N}
\end{array}
\end{aligned}
$$

Consequently, using the moment method to solve this system of integral equations a new $\mathbf{M}_{\mathrm{mn}}$ matrix is obtained with elements computed from

$$
\begin{aligned}
& \mathrm{M}_{\mathrm{mn}}=\frac{1}{4 \pi \varepsilon_{0}} \iint_{\Delta \mathrm{S}_{\mathrm{n}}}\left[\frac{1}{\left|r_{\mathrm{m}}-\hat{r}_{\mathrm{n}}^{\prime}\right|}-\frac{1}{\mid r_{\mathrm{m}}-r_{\mathrm{n}}^{\prime}}\right] \mathrm{dS}_{\mathrm{n}} \quad \begin{array}{l}
\mathrm{m}=1,2, \ldots, \mathrm{N}_{1} \\
\mathrm{n}=1,2, \ldots, \mathrm{N}
\end{array} \\
& \mathrm{M}_{\mathrm{mn}}=\frac{\varepsilon_{\mathrm{i}-\mathrm{Nc}}+\varepsilon_{\mathrm{i}+1-\mathrm{Nc}}}{2 \varepsilon_{0}\left(\varepsilon_{\mathrm{i}-\mathrm{Nc}}-\varepsilon_{\mathrm{i}+1-\mathrm{Nc})}\right)} \delta_{\mathrm{mn}}-\frac{1}{4 \pi \varepsilon_{0}} \iint_{\Delta \mathrm{S}_{\mathrm{m}}}\left|\frac{r_{\mathrm{m}}-\hat{r}_{\mathrm{n}}^{\prime}}{\left|r_{\mathrm{m}}-\hat{r}_{\mathrm{n}}^{\prime}\right|^{2}}\right| u_{\mathrm{y}} \mathrm{dS}_{\mathrm{m}} \\
&-\frac{1}{4 \pi \varepsilon_{0}} \iint_{\Delta \mathrm{S}_{\mathrm{m}}}\left|\frac{r_{\mathrm{m}}-r_{\mathrm{n}}^{\prime}}{\left|r_{\mathrm{m}}-r_{\mathrm{n}}^{\prime}\right|^{2}}\right| u_{\mathrm{y}} \mathrm{dS}_{\mathrm{m}} \quad \mathrm{m}=\mathrm{N}_{1}+1, \ldots, \mathrm{J}
\end{aligned}
$$

The double integrals given in (47) and (48) are discussed in detail in Appen$\operatorname{dix}$ B.

\section{RIGHT-ANGLE BENDS}

An interconnection line bend is the most common discontinuity in integrated circuits. A static lumped capacitance representation for this discontinuity is commonly used $^{7}$ in the microwave theory. The problem of the calculation of the lumped

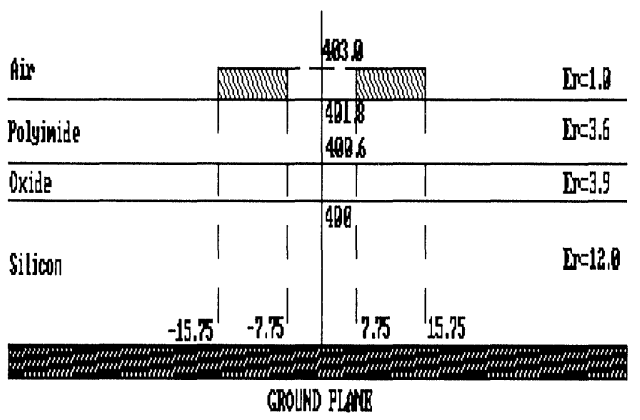

FIGURE 7 Dual interconnection line system 


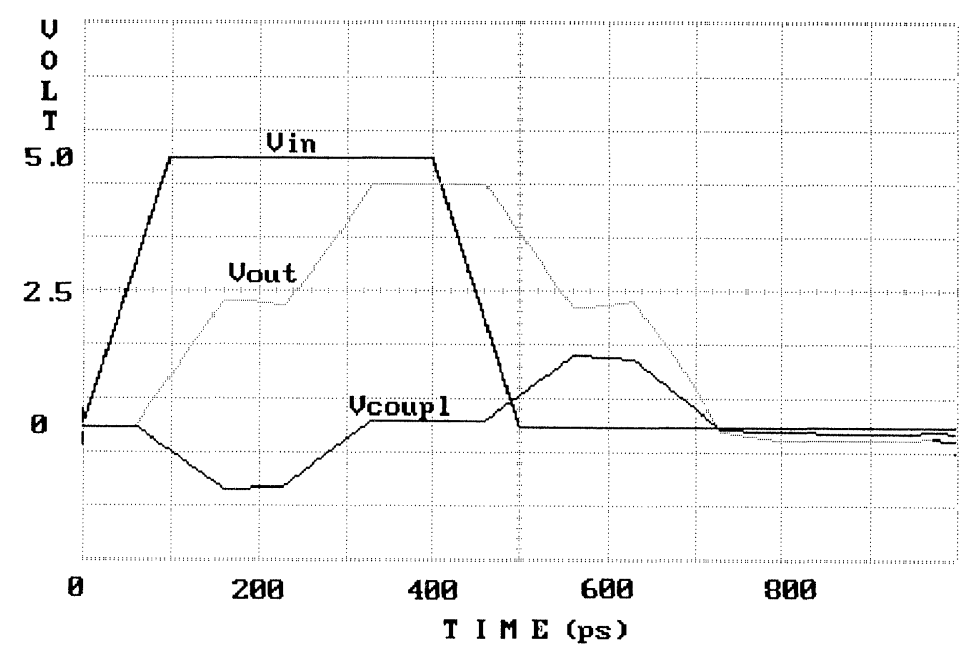

FIGURE 8 Time response of the dual line

capacitance of a right-angle bend of an interconnection line in multilayered dielectric media, can be solved using the section IV theory.

It is proposed that for the three-dimensional solutions only one cell along the sharp corners be decreased in width, since the total number of cells per conductor must necessarily be few. Further, for closely spaced conductors, the coupling capacitance depends on the center cell charge as well as the corner distribution, and thus the center of the conductor surfaces cannot be depleted of cells.

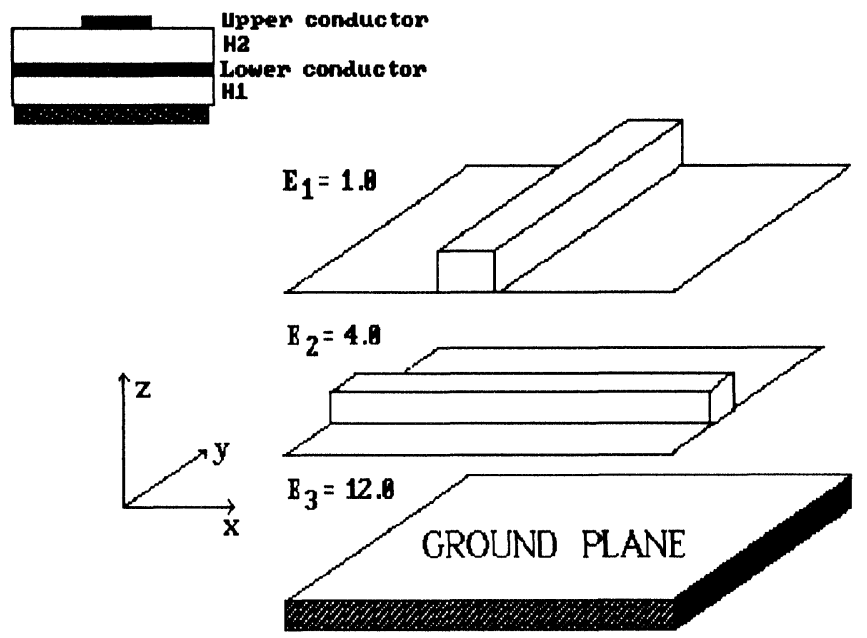

FIGURE 9 Crossing lines 
TABLE 1

Lumped capacitance values for example III.

\begin{tabular}{cc}
\hline $\mathrm{C}_{11}$ & $6.7847 \times 10^{-15}$ \\
$\mathrm{C}_{22}$ & $-7.317 \times 10^{-15}$ \\
$\mathrm{C}_{12}$ & $1.0780 \times 10^{-14}$ \\
\hline
\end{tabular}

\section{EXAMPLES}

\section{EXAMPLE I: A Single Interconnection Line}

To illustrate the numerical analysis developed here, a single interconnection line mounted above a ground plane has been considered, as shown in Fig. 4. Computing the characteristic impedance and the transmission velocity for the frequency of 10 $\mathrm{GHz}$ and for various widths (from 4 to $14 \mu \mathrm{m}$ ) gives the curves shown in Figs. 5 and 6 . Figure 5 shows the variation of the characteristic impedance of the line in respect to the width of the conductor for three substrate thickness (i.e. $200 \mu \mathrm{m}$, $300 \mu \mathrm{m}$ and $400 \mu \mathrm{m})$. Figure 6 shows the variation of the transmission velocity into the line with respect to the width of the conductor for three substrate thickness (i.e. $200 \mu \mathrm{m}, 300 \mu \mathrm{m}$ and $400 \mu \mathrm{m}$ ). The conductor is mounted above a ground plane and three dielectric layers are considered (Silicon, Silicon Oxide and Polyimide of thickness $400 \mu \mathrm{m}, 1.2 \mu \mathrm{m}$ and $0.6 \mu \mathrm{m}$ respectively). The conductor material is taken to be aluminum with a sheet resistance $R_{s}=0.01062 \mathrm{Ohm} / \mathrm{sq}$. at $1 \mathrm{GHz}$.

\section{EXAMPLE II: Dual Interconnection Line System}

A dual interconnection line system is considered, as shown in Fig. 7. There are three dielectric layers consisting from Silicon, Silicon Oxide and Polyimide with

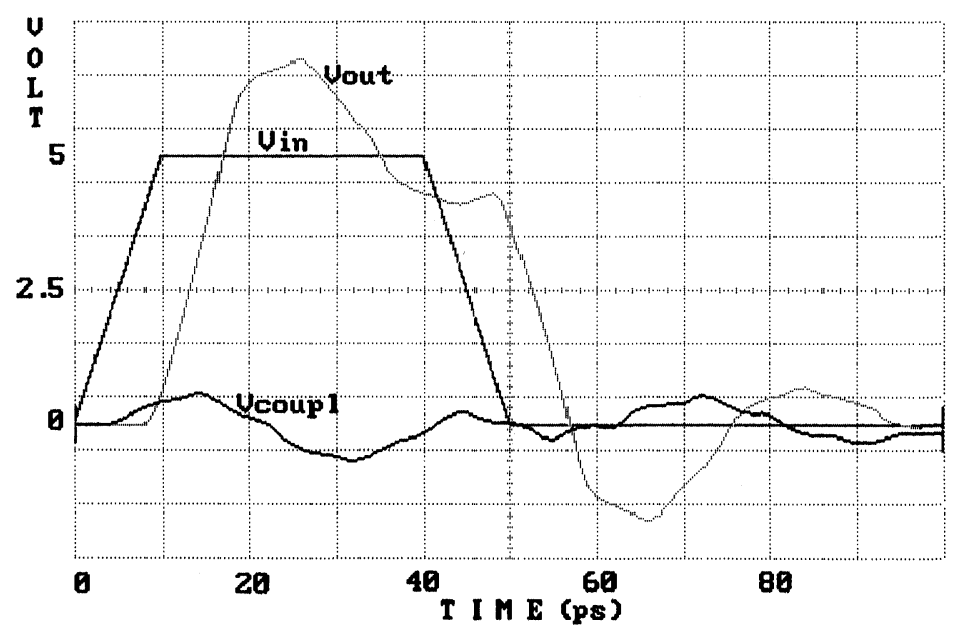

FIGURE 10 Time response of crossing interconnection line example 


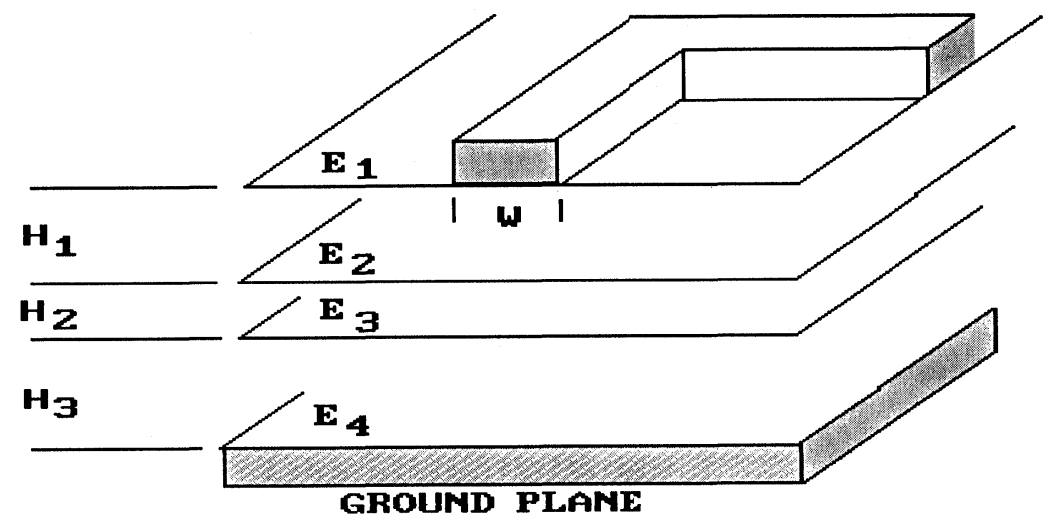

FIGURE 11 Right angle example

relative dielectric constants $12.0,3.9$ and 3.6 respectively. The material of the conductors is aluminium with a sheet resistance $R_{s}=0.01062 \mathrm{Ohm} / \mathrm{sq}$. at $1 \mathrm{GHz}$. The thickness of Silicon, Silicon Oxide and Polyimide are $400 \mu \mathrm{m}, 0.6 \mu \mathrm{m}$ and 1.2 $\mu \mathrm{m}$ respectively. The width of each conductor is $8 \mu \mathrm{m}$, their thickness is $2 \mu \mathrm{m}$ and the distance between them is $15 \mu \mathrm{m}$. Fig. 8 shows the response and the coupling at the end of this system, when we consider a pulse with rise and fall time values $100 \mathrm{ps}$, the width of pulse being $300 \mathrm{ps}$ and period $1 \mathrm{~ns}$ (a basic frequency of $1 \mathrm{GHz}$ ).

\section{EXAMPLE III: Crossing Lines}

Consider two crossed interconnection lines as shown in Fig. 9. The cross section of the conductors is orthogonal with dimensions $10 \mu \mathrm{m} \times 10 \mu \mathrm{m}$. The thickness of the adjacent dielectric layer is $400 \mu \mathrm{m}$ with a relative dielectric constant of 12.0 , while the middle dielectric layer has a relative dielectric constant of 4.0 and a height of $2 \mu \mathrm{m}$. Calculation of the equivalent lumped capacitance value gives the results shown in Table 1. In Fig. 10, the voltage at the end of the upper conductor and the voltage which is coupled at the second one, is given.

\section{EXAMPLE IV: Right-Angle Bend}

Consider a right-angle bend as shown in Fig. 11. The cross section of the conductor is orthogonal with height $2 \mu \mathrm{m}$ and a width, $\mathrm{W}$, which varies between $1.2 \mu \mathrm{m}$ and $4.0 \mu \mathrm{m}$. The thickness of the lower dielectric layer, $\mathrm{H}_{3}$, is varying between $200 \mu \mathrm{m}$ and $600 \mu \mathrm{m}$ and has a relative dielectric constant of 12.0. The other two dielectric

TABLE 2

Lumped capacitance values for example IV.

\begin{tabular}{llllll}
\hline $\mathrm{W} \mathrm{H}_{3}$ & $200 \mu \mathrm{m}$ & $300 \mu \mathrm{m}$ & $400 \mu \mathrm{m}$ & $500 \mu \mathrm{m}$ & $600 \mu \mathrm{m}$ \\
\hline 1.2 & 1.9233 & 1.9216 & 1.9208 & 1.9203 & 1.9199 \\
1.6 & 2.9409 & 2.9377 & 2.9361 & 2.9352 & 1.9346 \\
2.0 & 3.0206 & 3.0168 & 3.0147 & 3.0127 & 3.0127 \\
3.0 & 4.4676 & 4.3635 & 4.3596 & 4.3573 & 4.3555 \\
4.0 & 5.8270 & 5.8137 & 5.8069 & 5.8028 & 5.8001 \\
\hline
\end{tabular}


layers have relative dielectric constants 3.9 and 3.6 respectively, and heights 0.6 $\mu \mathrm{m}$ and $1.2 \mu \mathrm{m}$ respectively. Calculation of the lumped capacitance values gives the results shown in Table 2.

\section{CONCLUSIONS}

A self contained electrical parameters analysis and electrical modelling method for 2-D and 3-D lossy coupled multilayered on-chip interconnection system has been developed. The solution is derived by applying the method of moments and includes the effects of signal attenuation and signal dispersion encountered in fast transient waveform propagation. The important feature of the presented method is the conversion of the coupled transmission lines into a model that consists of lossy uncoupled lines and a modal decoupling network at the input and a complementary coupling network at the output end, which may be included as a subcircuit in a SPICE like analog simulator. Two examples of parallel interconnection lines have been given in order to show the application of the method in studying the pulse propagation characteristics. Two more examples are presented, one for the case of crossing lines in different layers (in order to study the coupling of these), and one for the capacitance computation of a right-angle bend.

The method can also be used for the electrical modelling of metallization discontinuities like T-junctions, bends and interconnection through vias.

\section{ACKNOWLEDGMENTS}

This work was partially supported by the European Economic Community under the ESPRIT project 2016-BASE.

\section{REFERENCES}

1. A. Ahmadouche, J. Chilo, "Optimum Computation of Capacitance Coefficients of Multilevel Interconnecting Lines for Advanced Package", IEEE Trans. on Components, Hybrids, and Manufacturing Technology 12, 124 (1989).

2. A.R. Djordjevic, T.K. Sarkar, R.E. Harrington, "Analysis of Lossy Transmission Lines with Arbitrary Nonlinear Terminal Networks" IEEE Trans. on Microwave Theory and Techniques 34, 600 (1986).

3. E.T. Lewis, "An Analysis of Interconnect Line Capacitance and Coupling for VLSI Circuits" Solid-State Electronics 27, 741 (1984).

4. Y. Fukuota, Q. Zhang, D.P. Neikirik, T. Itoh, "Analysis of Multilayer Interconnect Lines for a High-Speed Digital Integrated Circuit" IEEE Trans. on Microwave Theory and Techniques 33, 527 (1985).

5. J. Chilo, T. Arnaud, "Coupling Effects in the Time Domain for an Interconnecting Bus in HighSpeed GaAs Logic Circuits" IEEE Trans. on Electron Devices 31, 347 (1984).

6. J.R. Brews, "Transmission Line Models for Lossy Waveguide Interconnections in VLSI" IEEE Trans. on Electron Devices 33, 1356 (1986).

7. S. Seki, H. Hasegawa, "Analysis of Crosstalk in Very High-Speed LSI/VLSI's Using a Coupled Multiconductor MIS Microstrip Line Model” IEEE Trans. on Microwave Theory and Techniques 32, 1715 (1984).

8. C.J. Stanghan, B.M. Macdonald, "Electrical Characterization of Packages for High-Speed Integrated Circuits", IEEE Trans. on Components, Hybrids, and Manufacturing Technology 8, 468 (1985). 
9. V.K. Tripathy, R.J. Bucolo, "A Simple Network Analog Approach for the Quasi-Static Characteristics of General Lossy, Anisotropic, Layered Structures" IEEE Trans. on Microwave Theory and Techniques 33, 1458 (1985).

10. V.K. Tripathy, J.B. Retting, "A SPICE Model for Multiple Coupled Microstrips and other Transmission Lines", IEEE Trans. on Microwave Theory and Techniques 33, 1513 (1985).

11. R.F. Harrington, C. Wei, "Losses on Multiconductor Transmission Lines in Multilayered Dielectric Media", IEEE Trans. on Microwave Theory and Techniques 32, 705 (1984).

12. J. Kim, J.F. McDonald, "Transient and Crosstalk Analysis of Slightly Lossy Interconnection Lines for Wafer Scale Integration and Wafer Scale Hybrid Packing-Weak Coupling Case" IEEE Trans. on Circuits and Systems 35, 1369 (1988).

13. Z.G. Ning, P.M. Dewilde, F.L. Neerhoff, "Capacitance Coefficients for VLSI Multilevel Metallization Lines", IEEE Trans. on Electron Devices 34, 644 (1987).

14. W. Veit, H. Diestel, R. Pregla, "Coupling of Crossed Planar Multiconductor Systems" IEEE Trans. on Microwave Theory and Techniques 38, 265 (1990).

15. L. Wiemer, R.H. Jansen, "Determination of Coupling Capacitance of Underpasses, Air Bridges and Crossing in MICs and MMICs", Electronic Letters 23, 345 (1987).

16. R. Kamikawai, M. Nishi, K. Nakanishi, A. Masaki, "Electrical Parameter Analysis from ThreeDimensional Interconnection Geometry", IEEE Trans. on Components, Hybrids, and Manufacturing Technology 8, 269 (1985).

17. K.Z. Dimopoulos, J.N. Avaritsiotis, S.J. White "Electrical Modelling of Lossy On-Chip Multilevel Interconnecting Lines", IEEE proceeding of The European Conference on Design Automation, 106 (1991).

18. R.F. Harrington, "Field Computation by Moment Methods", (The Macmillan Company, NY, 1968).

19. A.R. Djordjevic, T.K. Sarkar, R.F. Harrington, "Time-Domain Response of Multiconductor Transmission Lines" Proc. of IEEE 75, 743 (1987).

20. H. Hasegawa, M. Furukawa, H. Yanai, "Properties of Microstrip Line on $\mathrm{Si}_{-} \mathrm{SiO}_{2} \mathrm{System}$ ", IEEE Trans. on Microwave Theory and Techniques 19, 869 (1971).

21. K.W. Goossen, R.B. Hammond, "Modeling of Picosecond Pulse Propagation in Microstrip Interconnections on Integrated Circuits", IEEE Trans. on Microwave Theory and Techniques 37, 459 (1989).

22. W.T. Weeks, "Calculation of Coefficients of Capacitance of Multiconductor Transmission Lines in the Presence of a Dielectric Interface" IEEE Trans. on Microwave Theory and Techniques 18 , 35 (1970).

23. C. Wei, R.F. Harrington, J.R. Mautz, T.K. Sarkar, "Multiconductor Transmission Lines in Multilayered Dielectric Media" IEEE Trans. on Microwave Theory and Techniques 32, 439 (1984).

24. F.Y. Chang, "Transient Analysis of Lossless Coupled Transmission Lines in a Nonhomogeneous Dielectric Medium" IEEE Trans. on Microwave Theory and Techniques 18, 616 (1970).

25. K.D. Marx, "Propagation Modes, Equivalent Circuits, and Characteristic Terminations for Multiconductor Transmission Lines with Inhomogeneous Dielectrics" IEEE Trans. on Microwave Theory and Techniques 21, 450 (1973).

26. P.D. Patel, "Calculation of Capacitance Coefficients for a System of Irregular Finite Conductors on a Dielectric Sheet", IEEE Trans. on Microwave Theory and Techniques 19, 862 (1971).

\section{APPENDIX A}

The evaluation of the double integrals of (14) and (16) depends on the position of the considered subsections. A closed form of these can be found in ${ }^{1}$. 
By introducing the following new set of variables:

$$
\begin{aligned}
& \mathrm{u}=\mathrm{x}_{\mathrm{m}}-\mathrm{x}_{\mathrm{n}} \\
& \mathrm{v}=\mathrm{y}_{\mathrm{m}}-\mathrm{y}_{\mathrm{n}}, \text { and } \\
& \mathrm{w}=\mathrm{y}_{\mathrm{m}}+\mathrm{y}_{\mathrm{n}}
\end{aligned}
$$

coefficients $M_{m n}$ are determined from:

$$
\begin{aligned}
& \left.\left.\int_{x_{m}} \int_{x_{n}} \ln \left(u^{2}+v^{2}\right) d x_{m} d x_{n}=F_{1}(u, v)\right]_{x_{n}}\right]_{x_{m}} \\
& \left.\left.\int_{x_{m}} \int_{x_{n}} \ln \left(u^{2}+w^{2}\right) d x_{m} d x_{n}=F_{1}(u, w)\right]_{x_{n}}\right]_{x_{m}} \\
& \left.\left.\int_{x_{m}} \int_{y_{n}} \ln \left(u^{2}+v^{2}\right) d x_{m} d y x_{n}=F_{2}(u, v)\right]_{y_{n}}\right]_{x_{m}} \\
& \left.\left.\int_{x_{m}} \int_{y_{n}} \ln \left(u^{2}+w^{2}\right) d x_{m} d x_{n}=-F_{2}(u, w)\right]_{y_{n}}\right]_{x_{m}} \\
& \left.\left.\int_{y_{m}} \int_{x_{n}} \ln \left(u^{2}+v^{2}\right) d x_{n} d x_{m}=F_{2}(v, u)\right]_{x_{n}}\right]_{y_{m}} \\
& \left.\left.\int_{y_{m}} \int_{y_{n}} \ln \left(u^{2}+v^{2}\right) d y_{n} d y_{m}=F_{1}(v, u)\right]_{y_{n}}\right]_{y_{m}} \\
& \left.\left.\int_{y_{m}} \int_{y_{n}} \ln \left(u^{2}+w^{2}\right) d y_{n} d y_{m}=-F_{1}(w, u)\right]_{y_{n}}\right]_{y_{m}} \\
& \left.\left.\int_{x_{m}} \int_{x_{n}} \frac{v}{u^{2}+v^{2}} d x_{n} d x_{m}=F_{3}(u, v)\right]_{x_{n}}\right]_{x_{m}} \\
& \left.\left.\int_{x_{m}} \int_{x_{n}} \frac{w}{u^{2}+w^{2}} d x_{n} d x_{m}=F_{3}(u, w)\right]_{x_{n}}\right]_{x_{m}} \\
& \left.\left.\int_{x_{m}} \int_{y_{n}} \frac{v}{u^{2}+v^{2}} d y_{n} d x_{m}=F_{4}(u, v)\right]_{y_{n}}\right]_{x_{m}} \\
& \left.\left.\int_{x_{m}} \int_{y_{n}} \frac{w}{u^{2}+w^{2}} d x_{m} d y_{m}=-F_{4}(u, w)\right]_{y_{n}}\right]_{x_{m}}
\end{aligned}
$$


where

$$
\begin{aligned}
& F_{1}(X, Y)=-\frac{X^{2}-Y^{2}}{2} \ln \left(X^{2}+Y^{2}\right)+\frac{3}{2} X^{2}-2 X Y \arctan \frac{X}{Y} \\
& F_{2}(X, Y)=-X Y \ln \left(X^{2}+Y^{2}\right)+3 X Y-X^{2} \arctan \frac{Y}{X}-Y^{2} \arctan \frac{X}{Y} \\
& F_{3}(X, Y)=-X \arctan \frac{X}{Y}+\frac{Y}{2} \ln \left(X^{2}+Y^{2}\right) \\
& F_{4}(X, Y)=-\frac{X}{2} \ln \left(X^{2}+Y^{2}\right)-Y \arctan \frac{X}{Y}
\end{aligned}
$$

\section{APPENDIX B}

The integrals given by (47) and (48) may be expressed in the following form ${ }^{26}$ :

$$
I_{k}=\int_{y_{n}-(D Y / 2)}^{y_{n}+(D Y / 2)} \int_{x_{n}-(D X / 2)}^{x_{n}+(D X / 2)} \frac{d y^{\prime} d x^{\prime}}{\left[g^{2}+\left(x_{m}-x^{\prime}\right)^{2}+\left(y_{m}-y^{\prime}\right)^{2}\right]^{1 / 2}}
$$

where DX and DY are the dimension of the subarea $\Delta s_{n}$.

Lettering $\mathrm{x}_{\mathrm{m}}-\mathrm{x}^{\prime}=\mathrm{X}$ and $\mathrm{y}_{\mathrm{m}}-\mathrm{y}^{\prime}=\mathrm{Y}$ one obtains:

$I_{k}=\int_{Y_{2}}^{Y_{1}} \int_{X_{2}}^{X_{1}} \frac{d y^{\prime} d x^{\prime}}{\left[g^{2}+\left(x_{m}-x^{\prime}\right)^{2}+\left(y_{m}-y^{\prime}\right)^{2}\right]^{1 / 2}}$

where

$$
\begin{array}{ll}
\mathrm{X}_{1}=\mathrm{x}_{\mathrm{m}}-\mathrm{x}_{\mathrm{n}}+\mathrm{DX} / 2 & \mathrm{Y}_{1}=\mathrm{y}_{\mathrm{m}}-\mathrm{y}_{\mathrm{n}}+\mathrm{DY} / 2 \\
\mathrm{X}_{2}=\mathrm{x}_{\mathrm{m}}-\mathrm{x}_{\mathrm{n}}-\mathrm{DX} / 2 & \mathrm{Y}_{2}=\mathrm{y}_{\mathrm{m}}-\mathrm{y}_{\mathrm{n}}-\mathrm{DY} / 2
\end{array}
$$

The previous equation may be integrated in a closed form and the result may be expressed in the following form:

$$
\begin{aligned}
& I_{k}=Y_{1}\left[\frac{X_{1}+X_{11}}{X_{2}+X_{21}}\right]-Y_{2} \ln \left[\frac{X_{1}+X_{12}}{X_{2}+X_{22}}\right]+X_{1} \ln \left[\frac{Y_{1}+X_{11}}{Y_{2}+X_{12}}\right] \\
&-X_{2} \ln \left[\frac{Y_{1}+X_{21}}{Y_{2}+X_{22}}\right]+g^{-1}\left[\frac{g X_{1}}{Z_{11}}\right]-g \tan ^{-1}\left[\frac{g X_{1}}{Z_{12}}\right] \\
&-g \tan ^{-1}\left[\frac{g X_{2}}{Z_{21}}\right]+g \tan ^{-1}\left[\frac{g X_{2}}{Z_{22}}\right]
\end{aligned}
$$

where

$$
\begin{aligned}
& X_{i j}=\left[g^{2}+X_{i}^{2}+Y_{j}^{2}\right]^{1 / 2} \\
& Z_{i j}=\left[g^{2}+Y_{j}^{2}+Y_{j} X_{i j}\right] \quad \text { for } i, j=1,2 .
\end{aligned}
$$



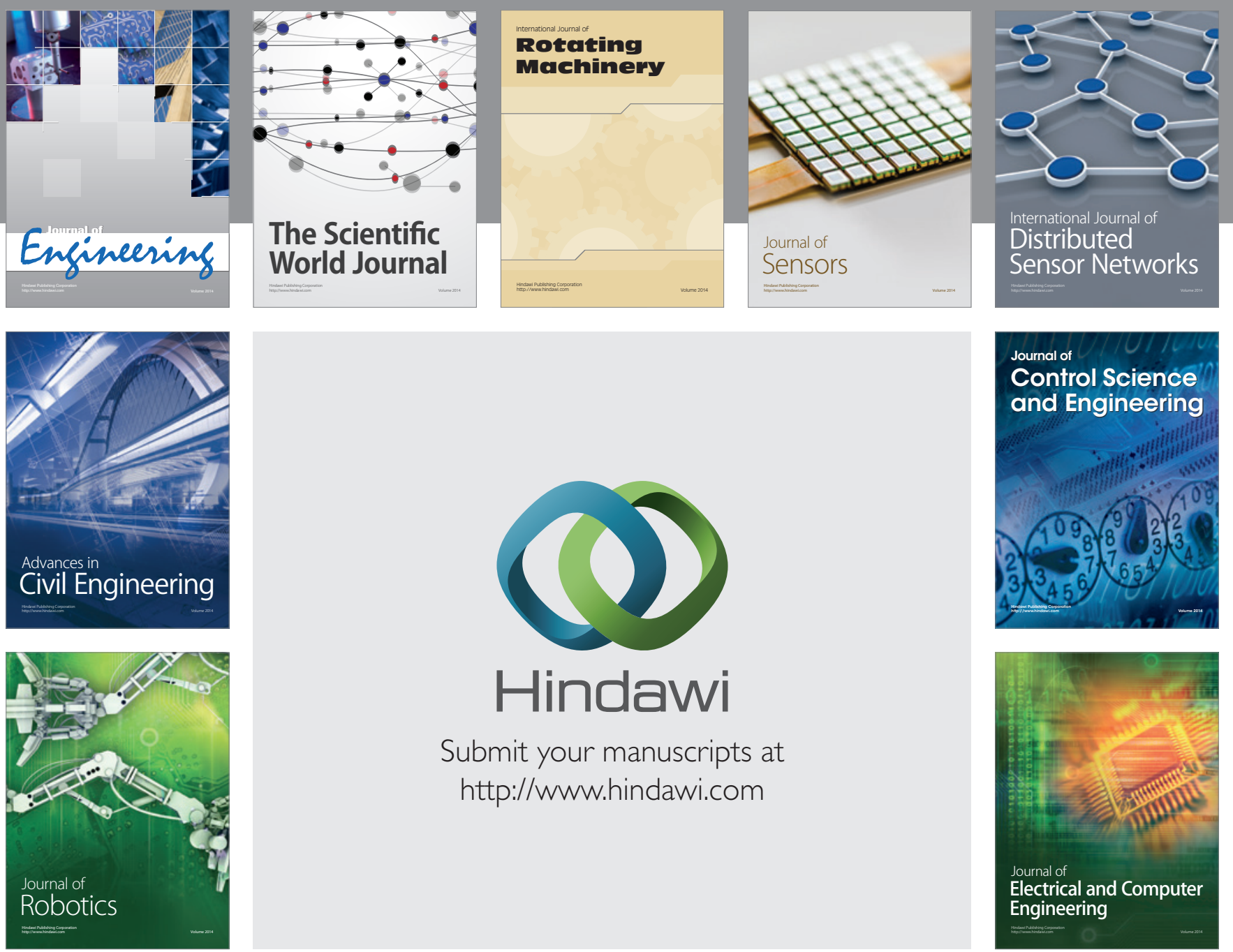

Submit your manuscripts at

http://www.hindawi.com
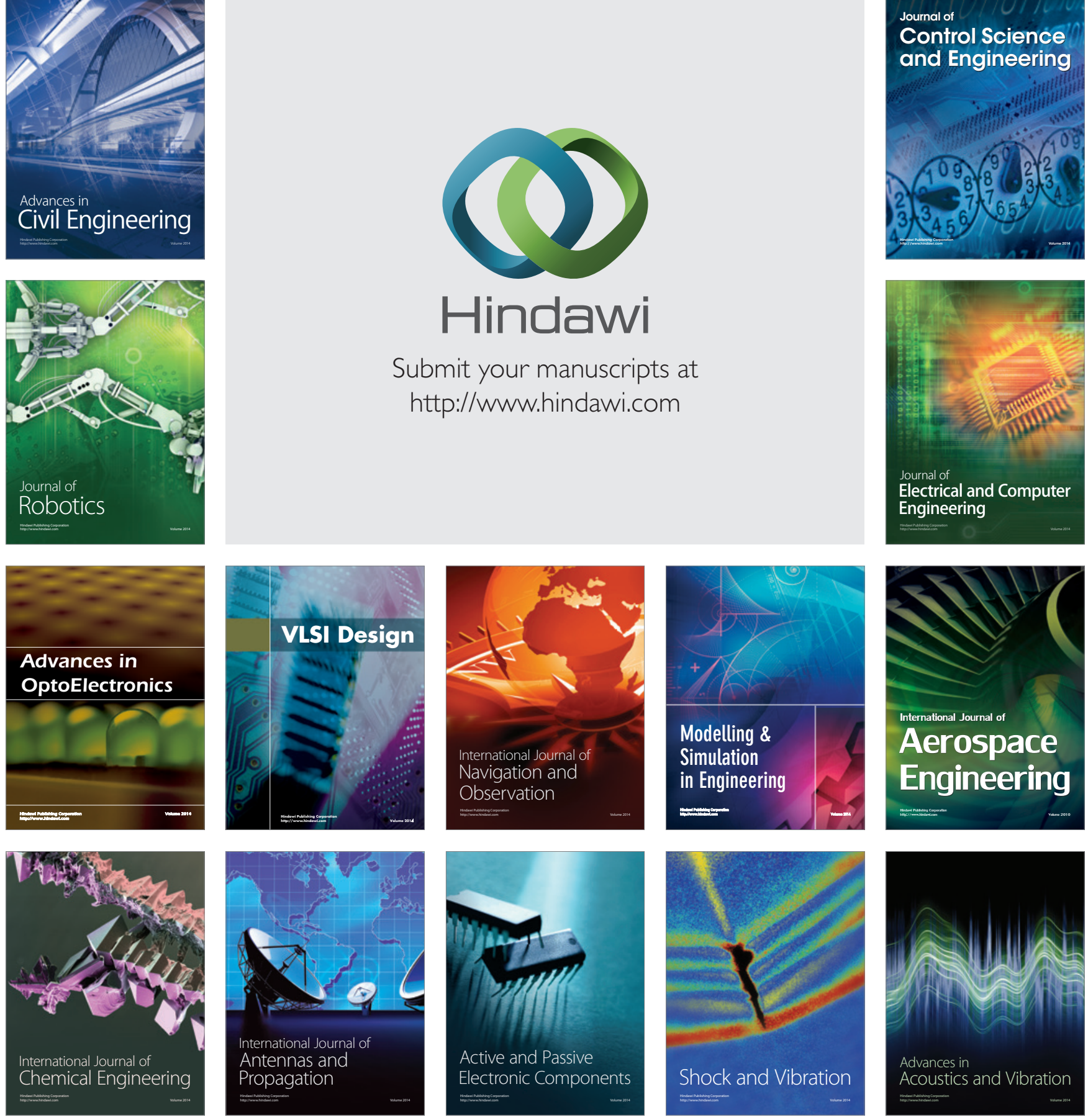